\title{
Using Similarity Software to Evaluate Scientific Paper Quality Is a Big Mistake
}

\section{Kuo-Chen Chou}

Gordon Life Science Institute, Boston, Massachusetts 02478, United States of America

Correspondence to: Kuo-Chen Chou, kcchou@gordonlifescience.org, kcchou38@gmail.com

Keywords: Similarity Check, 5-Steps Rule, PseAAC, PseKNC, Molecular Biology

Received: February 20, $2020 \quad$ Accepted: March 1, $2020 \quad$ Published: March 4, 2020

Copyright $\odot 2020$ by author(s) and Scientific Research Publishing Inc.

This work is licensed under the Creative Commons Attribution International License (CC BY 4.0).

http://creativecommons.org/licenses/by/4.0/

\section{(c) (i) Open Access}

\section{ABSTRACT}

Using similarity software to examine the quality of scientific papers is a nuisance. The significance of a scientific paper should be decided by the acknowledged experts. The practice of using the computer program to decide scientific papers must be rescinded or voided.

\section{INTRODUCTION}

The problem by using the similarity software to evaluate the quality of scientific papers is as follows. 1) For the classic laws, theorems [1], and rules [2], it is not allowed to change even one word. 2) In contrast, by using different words with essentially the same contents or ideas as the classic ones, so as to claim new findings or discovery to steal the credit. Unfortunately, the similarity software is unable to detect this kind of cheatings. 3) In many music tunes composed by Bach Johann Sebastian and Wolfgang Amadeus Mozart (two of the most productive and influential composers for all time), their similarities are extremely high, but their tunes have been highly appreciated until now and even forever.

\section{DISCUSSION}

To develop a really useful prediction method or predictor for a biological system, one needs to go through the following five steps: 1) select or construct a valid benchmark dataset to train and test the predictor; 2) represent the samples with an effective formulation that can truly reflect their intrinsic correlation with the target to be predicted; 3 ) introduce or develop a powerful algorithm to conduct the prediction; 4) properly perform cross-validation tests to objectively evaluate the anticipated prediction accuracy; 5) establish a user-friendly web-server for the predictor that is accessible to the public. Papers written in compliance with the guidelines of the 5-steps rules, also named by many as "Chou's 5-steps rule" [3-35], have the following notable merits: 1) crystal clear in logic development, 2) completely transparent in operation, 3) easily to repeat the reported results by other investigators, 4) with high potential in stimulating other sequence-analyzing methods, and 5) very convenient to be used by the majority of experimental scientists.

Also, one of the most challenging problems in computational biology today is how to effectively for- 
mulate the sequence of a biological sample (such as protein, peptide, DNA, or RNA) with a discrete model or a vector that can considerably keep its sequence order information or capture its key features. The reasons are as follows. 1) If using the sequential model, i.e., the model in which all the samples are represented by their original sequences, it is hardly able to train a machine that can cover all the possible cases concerned, as elaborated in [2].2) All the existing computational algorithms can only handle vector but not sequence samples. However, a vector defined in a discrete model may completely lose the sequence-order information. To cope with such a dilemma for proteomics and genomics systems, the approach of pseudo amino acid composition components $[36,37]$ and pseudo K-tuple nucleotide components, called by many as "Chou's PseAAC" and "PseKNC" [23, 38-202], have been proposed.

\section{CONCLUSION}

Using similarity software to evaluate scientific paper quality is completely meaningless. The practice of using the computer program to decide scientific papers must be rescinded or voided. The significance of a scientific paper should be decided by the acknowledged experts as well as by whether it is in compliance with the "5-steps rule", as indicated by some very impressive papers [203-210] and a series of very recent papers (see, e.g., [211-226]).

\section{CONFLICTS OF INTEREST}

The author declares no conflicts of interest regarding the publication of this paper.

\section{REFERENCES}

1. Chou, K.C. (1995) A Novel Approach to Predicting Protein Structural Classes in a (20-1)-D Amino Acid Composition Space. Proteins: Structure, Function \& Genetics, 21, 319-344. https://doi.org/10.1002/prot.340210406

2. Chou, K.C. (2011) Some Remarks on Protein Attribute Prediction and Pseudo Amino Acid Composition (50th Anniversary Year Review, 5-Steps Rule). Journal of Theoretical Biology, 273, 236-247. https://doi.org/10.1016/j.jtbi.2010.12.024

3. Butt, A.H. and Khan, Y.D. (2019) Prediction of S-Sulfenylation Sites Using Statistical Moments Based Features via Chou's 5-Step Rule. International Journal of Peptide Research and Therapeutics.

4. Awais, M., Hussain, W., Khan, Y.D., Rasool, N., Khan, S.A. and Chou, K.C. (2019) iPhosH-PseAAC: Identify Phosphohistidine Sites in Proteins by Blending Statistical Moments and Position Relative Features According to the Chou's 5-Step Rule and General Pseudo Amino Acid Composition. IEEE/ ACM Transactions on Computational Biology and Bioinformatics. https://www.ncbi.nlm.nih.gov/pubmed/31144645 https://doi.org/10.1109/TCBB.2019.2919025

5. Barukab, O., Khan, Y.D., Khan, S.A. and Chou, K.C. (2019) iSulfoTyr-PseAAC: Identify Tyrosine Sulfation Sites by Incorporating Statistical Moments via Chou's 5-Steps Rule and Pseudo Components. Current Genomics, 20, 306-320. http://www.eurekaselect.com/174277/article

6. Butt, A.H. and Khan, Y.D. (2019) Prediction of S-Sulfenylation Sites Using Statistical Moments Based Features via Chou's 5-Step Rule. International Journal of Peptide Research and Therapeutics.

7. Chen, Y. and Fan, X. (2019) Use Chou's 5-Steps Rule to Reveal Active Compound and Mechanism of Shuangsheng Pingfei San on Idiopathic Pulmonary Fibrosis. Current Molecular Medicine, 20, 220-230.

8. Du, X., Diao, Y., Liu, H. and Li, S. (2019) MsDBP: Exploring DNA-Binding Proteins by Integrating Multi-Scale Sequence Information via Chou's 5-Steps Rule. Journal of Proteome Research, 18, 3119-3132.

https://doi.org/10.1021/acs.jproteome.9b00226

9. Dutta, A., Dalmia, A., R, A., Singh, K.K. and Anand, A. (2019) Using the Chou's 5-Steps Rule to Predict Splice Junctions with Interpretable Bidirectional Long Short-Term Memory Networks. Computers in Biology and 
Medicine, 116, Article ID: 103558. https://doi.org/10.1016/j.compbiomed.2019.103558

10. Ehsan, A., Mahmood, M.K., Khan, Y.D., Barukab, O.M., Khan, S.A. and Chou, K.C. (2019) iHyd-PseAAC (EPSV): Identify Hydroxylation Sites in Proteins by Extracting Enhanced Position and Sequence Variant Feature via Chou's 5-Step Rule and General Pseudo Amino Acid Composition. Current Genomics, 20, 124-133. https://doi.org/10.2174/1389202920666190325162307

11. Hussain, W., Khan, S.D., Rasool, N., Khan, S.A. and Chou, K.C. (2019) SPalmitoylC-PseAAC: A Sequence-Based Model Developed via Chou's 5-Steps Rule and General PseAAC for Identifying S-Palmitoylation Sites in Proteins. Analytical Biochemistry, 568, 14-23. https://doi.org/10.1016/j.ab.2018.12.019

12. Hussain, W., Khan, Y.D., Rasool, N., Khan, S.A. and Chou, K.C. (2019) SPrenylC-PseAAC: A Sequence-Based Model Developed via Chou's 5-Steps Rule and General PseAAC for Identifying S-Prenylation Sites in Proteins. Journal of Theoretical Biology, 468, 1-11. https://doi.org/10.1016/j.jtbi.2019.02.007

13. Khan, S., Khan, M., Iqbal, N., Hussain, T., Khan, S.A. and Chou, K.C. (2019) A Two-Level Computation Model Based on Deep Learning Algorithm for Identification of piRNA and Their Functions via Chou's 5-Steps Rule. International Journal of Peptide Research and Therapeutics. https://link.springer.com/article/10.1007\%2Fs10989-019-09887-3

14. Khan, Z.U., Ali, F., Khan, I.A., Hussain, Y. and Pi, D. (2019) iRSpot-SPI: Deep Learning-Based Recombination Spots Prediction by Incorporating Secondary Sequence Information Coupled with Physio-Chemical Properties via Chou's 5-Step Rule and Pseudo Components. Chemometrics and Intelligent Laboratory Systems (CHEMOLAB), 189, 169-180. https://doi.org/10.1016/j.chemolab.2019.05.003

15. Lan, J., Liu, J., Liao, C., Merkler, D.J., Han, Q. and Li, J. (2019) A Study for Therapeutic Treatment against Parkinson's Disease via Chou's 5-Steps Rule. Current Topics in Medicinal Chemistry, 19, 2318-2333. http://www.eurekaselect.com/175887/article

16. Le, N.Q.K. (2019) iN6-Methylat (5-Step): Identifying DNA N(6)-Methyladenine Sites in Rice Genome Using Continuous Bag of Nucleobases via Chou's 5-Step Rule. Molecular Genetics and Genomics. MGG, 294, 1173-1182. https://doi.org/10.1007/s00438-019-01570-y

17. Le, N.Q.K., Yapp, E.K.Y., Ho, Q.T., Nagasundaram, N., Ou, Y.Y. and Yeh, H.Y. (2019) iEnhancer-5Step: Identifying Enhancers Using Hidden Information of DNA Sequences via Chou's 5-Step Rule and Word Embedding. Analytical Biochemistry, 571, 53-61. https://doi.org/10.1016/j.ab.2019.02.017

18. Le, N.Q.K., Yapp, E.K.Y., Ou, Y.Y. and Yeh, H.Y. (2019) iMotor-CNN: Identifying Molecular Functions of Cytoskeleton Motor Proteins Using 2D Convolutional Neural Network via Chou's 5-Step Rule. Analytical Biochemistry, 575, 17-26. https://doi.org/10.1016/j.ab.2019.03.017

19. Liang, R., Xie, J., Zhang, C., Zhang, M., Huang, H., Huo, H., Cao, X. and Niu, B. (2019) Identifying Cancer Targets Based on Machine Learning Methods via Chou's 5-Steps Rule and General Pseudo Components. Current Topics in Medical Chemistry, 19, 2301-2317. https://doi.org/10.2174/1568026619666191016155543

20. Liang, Y. and Zhang, S. (2019) Identifying DNase I Hypersensitive Sites Using Multi-Features Fusion and F-Score Features Selection via Chou's 5-Steps Rule. Biophysical Chemistry, 253, Article ID: 106227. https://doi.org/10.1016/j.bpc.2019.106227

21. Liu, Z., Dong, W., Jiang, W. and He, Z. (2019) csDMA: An Improved Bioinformatics Tool for Identifying DNA 6 mA Modifications via Chou's 5-Step Rule. Scientific Reports, 9, Article No. 13109.

https://doi.org/10.1038/s41598-019-49430-4

22. Malebary, S.J., Rehman, M.S.U. and Khan, Y.D. (2019) iCrotoK-PseAAC: Identify Lysine Crotonylation Sites by Blending Position Relative Statistical Features According to the Chou's 5-Step Rule. PLoS ONE, 14, e0223993. https://doi.org/10.1371/journal.pone.0223993 
23. Nazari, I., Tahir, M., Tayari, H. and Chong, K.T. (2019) iN6-Methyl (5-Step): Identifying RNA N6-methyladenosine Sites Using Deep Learning Mode via Chou's 5-Step Rules and Chou's General PseKNC. Chemometrics and Intelligent Laboratory Systems, 193, Article ID: 103811. https://doi.org/10.1016/j.chemolab.2019.103811

24. Ning, Q., Ma, Z. and Zhao, X. (2019) dForml(KNN)-PseAAC: Detecting Formylation Sites from Protein Sequences Using K-Nearest Neighbor Algorithm via Chou's 5-Step Rule and Pseudo Components. Journal of Theoretical Biology, 470, 43-49. https://doi.org/10.1016/j.jtbi.2019.03.011

25. Tahir, M., Tayara, H. and Chong, K.T. (2019) iDNA6mA (5-Step Rule): Identification of DNA N6-methyladenine Sites in the Rice Genome by Intelligent Computational Model via Chou's 5-Step Rule. CHEMOLAB, 189, 96-101. https://doi.org/10.1016/j.chemolab.2019.04.007

26. Wiktorowicz, A., Wit, A., Dziewierz, A., Rzeszutko, L., Dudek, D. and Kleczynski, P. (2019) Calcium Pattern Assessment in Patients with Severe Aortic Stenosis via the Chou's 5-Steps Rule. Current Pharmaceutical Design, 25, 3769-3775.

27. Yang, L., Lv, Y., Wang, S., Zhang, Q., Pan, Y., Su, D., Lu, Q. and Zuo, Y. (2019) Identifying FL11 Subtype by Characterizing Tumor Immune Microenvironment in Prostate Adenocarcinoma via Chou's 5-Steps Rule. Genomics, 112, 1500-1515.

28. Akbar, S., Rahman, A.U. and Hayat, M. (2020) cACP: Classifying Anticancer Peptides Using Discriminative Intelligent Model via Chou's 5-Step Rules and General Pseudo Components. Chemometrics and Intelligent Laboratory (CHEMOLAB), 196, Article ID: 103912. https://doi.org/10.1016/j.chemolab.2019.103912

29. Charoenkwan, P., Schaduangrat, N., Nantasenamat, C., Piacham, T. and Shoombuatong, W. (2020) iQSP: A Sequence-Based Tool for the Prediction and Analysis of Quorum Sensing Peptides via Chou's 5-Steps Rule and Informative Physicochemical Properties. International Journal of Molecular Sciences, 21, 75. https://doi.org/10.3390/ijms21010075

30. Dobosz, R., Mucko, J. and Gawinecki, R. (2020) Using Chou's 5-Step Rule to Evaluate the Stability of Tautomers: Susceptibility of 2-[(Phenylimino)-methyl]-cyclohexane-1,3-diones to Tautomerization Based on the Calculated Gibbs Free Energies. Energies, 13, 183. https://doi.org/10.3390/en13010183

31. Ju, Z. and Wang, S.Y. (2020) Prediction of Lysine Formylation Sites Using the Composition of k-Spaced Amino Acid Pairs via Chou's 5-Steps Rule and General Pseudo Components. Genomics, 112, 859-866. https://doi.org/10.1016/j.ygeno.2019.05.027

32. Kabir, M., Ahmad, S., Iqbal, M. and Hayat, M. (2020) iNR-2L: A Two-Level Sequence-Based Predictor Developed via Chou's 5-Steps Rule and General PseAAC for Identifying Nuclear Receptors and Their Families. Genomics, 112, 276-285. https://doi.org/10.1016/j.ygeno.2019.02.006

33. Khan, Y.D., Amin, N., Hussain, W., Rasool, N., Khan, S.A. and Chou, K.C. (2020) iProtease-PseAAC(2L): A Two-Layer Predictor for Identifying Proteases and Their Types Using Chou's 5-Step-Rule and General PseAAC. Analytical Biochemistry, 588, Article ID: 113477. https://doi.org/10.1016/j.ab.2019.113477

34. Vishnoi, S., Garg, P. and Arora, P. (2020) Physicochemical n-Grams Tool: A Tool for Protein Physicochemical Descriptor Generation via Chou's 5-Step Rule. Chemical Biology \& Drug Design, 95, 79-86. https://doi.org/10.1111/cbdd.13617

35. Vundavilli, H., Datta, A., Sima, C., Hua, J., Lopes, R. and Bittner, M. (2020) Using Chou's 5-Steps Rule to Model Feedback in Lung Cancer. IEEE Journal of Biomedical and Health Informatics. https://doi.org/10.1109/JBHI.2019.2958042

36. Chou, K.C. (2001) Prediction of Protein Cellular Attributes Using Pseudo Amino Acid Composition. PROTEINS: Structure, Function, and Genetics, 43, 246-255. https://doi.org/10.1002/prot.1035 
37. Chou, K.C. (2005) Using Amphiphilic Pseudo Amino Acid Composition to Predict Enzyme Subfamily Classes. Bioinformatics, 21, 10-19. https://doi.org/10.1093/bioinformatics/bth466

38. Ding, Y.S. and Zhang, T.L. (2008) Using Chou's Pseudo Amino Acid Composition to Predict Subcellular Localization of Apoptosis Proteins: An Approach with Immune Genetic Algorithm-Based Ensemble Classifier. Pattern Recognition Letters, 29, 1887-1892. https://doi.org/10.1016/j.patrec.2008.06.007

39. Fang, Y., Guo, Y., Feng, Y. and Li, M. (2008) Predicting DNA-Binding Proteins: Approached from Chou's Pseudo Amino Acid Composition and Other Specific Sequence Features. Amino Acids, 34, 103-109. https://doi.org/10.1007/s00726-007-0568-2

40. Jiang, X., Wei, R., Zhang, T.L. and Gu, Q. (2008) Using the Concept of Chou's Pseudo Amino Acid Composition to Predict Apoptosis Proteins Subcellular Location: An Approach by Approximate Entropy. Protein \& Peptide Letters, 15, 392-396. https://doi.org/10.2174/092986608784246443

41. Jiang, X., Wei, R., Zhao, Y. and Zhang, T. (2008) Using Chou's Pseudo Amino Acid Composition Based on Approximate Entropy and an Ensemble of AdaBoost Classifiers to Predict Protein Subnuclear Location. Amino Acids, 34, 669-675. https://doi.org/10.1007/s00726-008-0034-9

42. Li, F.M. and Li, Q.Z. (2008) Predicting Protein Subcellular Location Using Chou's Pseudo Amino Acid Composition and Improved Hybrid Approach. Protein \& Peptide Letters, 15, 612-616.

https://doi.org/10.2174/092986608784966930

43. Lin, H. (2008) The Modified Mahalanobis Discriminant for Predicting Outer Membrane Proteins by Using Chou's Pseudo Amino Acid Composition. Journal of Theoretical Biology, 252, 350-356.

https://doi.org/10.1016/j.jtbi.2008.02.004

44. Lin, H., Ding, H., Guo, F.B., Zhang, A.Y. and Huang, J. (2008) Predicting Subcellular Localization of Mycobacterial Proteins by Using Chou's Pseudo Amino Acid Composition. Protein \& Peptide Letters, 15, 739-744. https://doi.org/10.2174/092986608785133681

45. Nanni, L. and Lumini, A. (2008) Genetic Programming for Creating Chou's Pseudo Amino Acid Based Features for Submitochondria Localization. Amino Acids, 34, 653-660. https://doi.org/10.1007/s00726-007-0018-1

46. Zhang, G.Y., Li, H.C., Gao, J.Q. and Fang, B.S. (2008) Predicting Lipase Types by Improved Chou's Pseudo Amino Acid Composition. Protein \& Peptide Letters, 15, 1132-1137. https://doi.org/10.2174/092986608786071184

47. Zhang, S.W., Chen, W., Yang, F. and Pan, Q. (2008) Using Chou's Pseudo Amino Acid Composition to Predict Protein Quaternary Structure: A Sequence-Segmented PseAAC Approach. Amino Acids, 35, 591-598. https://doi.org/10.1007/s00726-008-0086-x

48. Zhang, S.W., Zhang, Y.L., Yang, H.F., Zhao, C.H. and Pan, Q. (2008) Using the Concept of Chou's Pseudo Amino Acid Composition to Predict Protein Subcellular Localization: An Approach by Incorporating Evolutionary Information and Von Neumann Entropies. Amino Acids, 34, 565-572.

https://doi.org/10.1007/s00726-007-0010-9

49. Chen, C., Chen, L., Zou, X. and Cai, P. (2009) Prediction of Protein Secondary Structure Content by Using the Concept of Chou's Pseudo Amino Acid Composition and Support Vector Machine. Protein \& Peptide Letters, 16, 27-31. https://doi.org/10.2174/092986609787049420

50. Georgiou, D.N., Karakasidis, T.E., Nieto, J.J. and Torres, A. (2009) Use of Fuzzy Clustering Technique and Matrices to Classify Amino Acids and Its Impact to Chou's Pseudo Amino Acid Composition. Journal of Theoretical Biology, 257, 17-26. https://doi.org/10.1016/j.jtbi.2008.11.003

51. Li, Z.C., Zhou, X.B., Dai, Z. and Zou, X.Y. (2009) Prediction of Protein Structural Classes by Chou's Pseudo Amino Acid Composition: Approached Using Continuous Wavelet Transform and Principal Component Anal- 
ysis. Amino Acids, 37, 415-425. https://doi.org/10.1007/s00726-008-0170-2

52. Lin, H., Wang, H., Ding, H., Chen, Y.L. and Li, Q.Z. (2009) Prediction of Subcellular Localization of Apoptosis Protein Using Chou's Pseudo Amino Acid Composition. Acta Biotheoretica, 57, 321-330. https://doi.org/10.1007/s10441-008-9067-4

53. Qiu, J.D., Huang, J.H., Liang, R.P. and Lu, X.Q. (2009) Prediction of G-Protein-Coupled Receptor Classes Based on the Concept of Chou's Pseudo Amino Acid Composition: An Approach from Discrete Wavelet Transform. Analytical Biochemistry, 390, 68-73. https://doi.org/10.1016/j.ab.2009.04.009

54. Zeng, Y.H., Guo, Y.Z., Xiao, R.Q., Yang, L., Yu, L.Z. and Li, M.L. (2009) Using the Augmented Chou's Pseudo Amino Acid Composition for Predicting Protein Submitochondria Locations Based on Auto Covariance Approach. Journal of Theoretical Biology, 259, 366-372. https://doi.org/10.1016/j.jtbi.2009.03.028

55. Esmaeili, M., Mohabatkar, H. and Mohsenzadeh, S. (2010) Using the Concept of Chou's Pseudo Amino Acid Composition for Risk Type Prediction of Human Papillomaviruses. Journal of Theoretical Biology, 263, 203-209. https://doi.org/10.1016/j.jtbi.2009.11.016

56. Gu, Q., Ding, Y.S. and Zhang, T.L. (2010) Prediction of G-Protein-Coupled Receptor Classes in Low Homology Using Chou's Pseudo Amino Acid Composition with Approximate Entropy and Hydrophobicity Patterns. Protein \& Peptide Letters, 17, 559-567. https://doi.org/10.2174/092986610791112693

57. Mohabatkar, H. (2010) Prediction of Cyclin Proteins Using Chou's Pseudo Amino Acid Composition. Protein \& Peptide Letters, 17, 1207-1214. https://doi.org/10.2174/092986610792231564

58. Qiu, J.D., Huang, J.H., Shi, S.P. and Liang, R.P. (2010) Using the Concept of Chou's Pseudo Amino Acid Composition to Predict Enzyme Family Classes: An Approach with Support Vector Machine Based on Discrete Wavelet Transform. Protein \& Peptide Letters, 17, 715-722. https://doi.org/10.2174/092986610791190372

59. Sahu, S.S. and Panda, G. (2010) A Novel Feature Representation Method Based on Chou's Pseudo Amino Acid Composition for Protein Structural Class Prediction. Computational Biology and Chemistry, 34, 320-327. https://doi.org/10.1016/j.compbiolchem.2010.09.002

60. Yu, L., Guo, Y., Li, Y., Li, G., Li, M., Luo, J., Xiong, W. and Qin, W. (2010) SecretP: Identifying Bacterial Secreted Proteins by Fusing New Features into Chou's Pseudo Amino Acid Composition. Journal of Theoretical Biology, 267, 1-6. https://doi.org/10.1016/j.jtbi.2010.08.001

61. Guo, J., Rao, N., Liu, G., Yang, Y. and Wang, G. (2011) Predicting Protein Folding Rates Using the Concept of Chou's Pseudo Amino Acid Composition. Journal of Computational Chemistry, 32, 1612-1617. https://doi.org/10.1002/jcc. 21740

62. Lin, J. and Wang, Y. (2011) Using a Novel AdaBoost Algorithm and Chou's Pseudo Amino Acid Composition for Predicting Protein Subcellular Localization. Protein \& Peptide Letters, 18, 1219-1225. https://doi.org/10.2174/092986611797642797

63. Lin, J., Wang, Y. and Xu, X. (2011) A Novel Ensemble and Composite Approach for Classifying Proteins Based on Chou's Pseudo Amino Acid Composition. African Journal of Biotechnology, 10, 16963-16968.

https://doi.org/10.5897/AJB11.429

64. Mohabatkar, H., Mohammad Beigi, M. and Esmaeili, A. (2011) Prediction of GABA(A) Receptor Proteins Using the Concept of Chou's Pseudo Amino Acid Composition and Support Vector Machine. Journal of Theoretical Biology, 281, 18-23. https://doi.org/10.1016/j.jtbi.2011.04.017

65. Mohammad, B.M., Behjati, M. and Mohabatkar, H. (2011) Prediction of Metalloproteinase Family Based on the Concept of Chou's Pseudo Amino Acid Composition Using a Machine Learning Approach. Journal of Structural and Functional Genomics, 12, 191-197. https://doi.org/10.1007/s10969-011-9120-4

66. Qiu, J.D., Suo, S.B., Sun, X.Y., Shi, S.P. and Liang, R.P. (2011) OligoPred: A Web-Server for Predicting Ho- 
mo-Oligomeric Proteins by Incorporating Discrete Wavelet Transform into Chou's Pseudo Amino Acid Composition. Journal of Molecular Graphics \& Modelling, 30, 129-134. https://doi.org/10.1016/j.jmgm.2011.06.014

67. Zou, D., He, Z., He, J. and Xia, Y. (2011) Supersecondary Structure Prediction Using Chou's Pseudo Amino Acid Composition. Journal of Computational Chemistry, 32, 271-278. https://doi.org/10.1002/jcc.21616

68. Cao, J.Z., Liu, W.Q. and Gu, H. (2012) Predicting Viral Protein Subcellular Localization with Chou's Pseudo Amino Acid Composition and Imbalance-Weighted Multi-Label K-Nearest Neighbor Algorithm. Protein and Peptide Letters, 19, 1163-1169. https://doi.org/10.2174/092986612803216999

69. Chen, C., Shen, Z.B. and Zou, X.Y. (2012) Dual-Layer Wavelet SVM for Predicting Protein Structural Class via the General Form of Chou's Pseudo Amino Acid Composition. Protein \& Peptide Letters, 19, 422-429. https://doi.org/10.2174/092986612799789332

70. Du, P., Wang, X., Xu, C. and Gao, Y. (2012) PseAAC-Builder: A Cross-Platform Stand-Alone Program for Generating Various Special Chou's Pseudo Amino Acid Compositions. Analytical Biochemistry, 425, 117-119. https://doi.org/10.1016/j.ab.2012.03.015

71. Fan, G.L. and Li, Q.Z. (2012) Predict Mycobacterial Proteins Subcellular Locations by Incorporating Pseudo-Average Chemical Shift into the General form of Chou's Pseudo Amino Acid Composition. Journal of Theoretical Biology, 304, 88-95. https://doi.org/10.1016/j.jtbi.2012.03.017

72. Fan, G.L. and Li, Q.Z. (2012) Predicting Protein Submitochondria Locations by Combining Different Descriptors into the General form of Chou's Pseudo Amino Acid Composition. Amino Acids, 43, 545-555.

https://doi.org/10.1007/s00726-011-1143-4

73. Hayat, M. and Khan, A. (2012) Discriminating Outer Membrane Proteins with Fuzzy K-Nearest Neighbor Algorithms Based on the General Form of Chou's PseAAC. Protein \& Peptide Letters, 19, 411-421. https://doi.org/10.2174/092986612799789387

74. Li, L.Q., Zhang, Y., Zou, L.Y., Zhou, Y. and Zheng, X.Q. (2012) Prediction of Protein Subcellular Multi-Localization Based on the General form of Chou's Pseudo Amino Acid Composition. Protein \& Peptide Letters, 19, 375-387. https://doi.org/10.2174/092986612799789369

75. Liao, B., Xiang, Q. and Li, D. (2012) Incorporating Secondary Features into the General form of Chou's PseAAC for Predicting Protein Structural Class. Protein \& Peptide Letters, 19, 1133-1138. https://doi.org/10.2174/092986612803217051

76. Liu, L., Hu, X.Z., Liu, X.X., Wang, Y. and Li, S.B. (2012) Predicting Protein Fold Types by the General Form of Chou's Pseudo Amino Acid Composition: Approached from Optimal Feature Extractions. Protein \& Peptide Letters, 19, 439-449. https://doi.org/10.2174/092986612799789378

77. Mei, S. (2012) Multi-Kernel Transfer Learning Based on Chou's PseAAC Formulation for Protein Submitochondria Localization. Journal of Theoretical Biology, 293, 121-130. https://doi.org/10.1016/j.jtbi.2011.10.015

78. Mei, S. (2012) Predicting Plant Protein Subcellular Multi-Localization by Chou's PseAAC Formulation Based Multi-Label Homolog Knowledge Transfer Learning. Journal of Theoretical Biology, 310, 80-87. https://doi.org/10.1016/j.jtbi.2012.06.028

79. Nanni, L., Brahnam, S. and Lumini, A. (2012) Wavelet Images and Chou's Pseudo Amino Acid Composition for Protein Classification. Amino Acids, 43, 657-665. https://doi.org/10.1007/s00726-011-1114-9

80. Nanni, L., Lumini, A., Gupta, D. and Garg, A. (2012) Identifying Bacterial Virulent Proteins by Fusing a Set of Classifiers Based on Variants of Chou's Pseudo Amino Acid Composition and on Evolutionary Information. IEEE ACM Transaction on Computational Biology and Bioinformatics, 9, 467-475. https://doi.org/10.1109/TCBB.2011.117 
81. Niu, X.H., Hu, X.H., Shi, F. and Xia, J.B. (2012) Predicting Protein Solubility by the General Form of Chou's Pseudo Amino Acid Composition: Approached from Chaos Game Representation and Fractal Dimension. Protein \& Peptide Letters, 19, 940-948. https://doi.org/10.2174/092986612802084492

82. Qin, Y.F., Wang, C.H., Yu, X.Q., Zhu, J., Liu, T.G. and Zheng, X.Q. (2012) Predicting Protein Structural Class by Incorporating Patterns of Over-Represented K-MERS into the General Form of Chou's PseAAC. Protein \& Peptide Letters, 19, 388-397. https://doi.org/10.2174/092986612799789350

83. Ren, L.Y., Zhang, Y.S. and Gutman, I. (2012) Predicting the Classification of Transcription Factors by Incorporating Their Binding Site Properties into a Novel Mode of Chou's Pseudo Amino Acid Composition. Protein \& Peptide Letters, 19, 1170-1176. https://doi.org/10.2174/092986612803217088

84. Sun, X.Y., Shi, S.P., Qiu, J.D., Suo, S.B., Huang, S.Y. and Liang, R.P. (2012) Identifying Protein Quaternary Structural Attributes by Incorporating Physicochemical Properties into the General Form of Chou's PseAAC via Discrete Wavelet Transform. Molecular BioSystems, 8, 3178-3184. https://doi.org/10.1039/c2mb25280e

85. Zhao, X.W., Ma, Z.Q. and Yin, M.H. (2012) Predicting Protein-Protein Interactions by Combing Various Sequence-Derived Features into the General form of Chou's Pseudo Amino Acid Composition. Protein \& Peptide Letters, 19, 492-500. https://doi.org/10.2174/092986612800191080

86. Zia-ur-Rehman and Khan, A. (2012) Identifying GPCRs and Their Types with Chou's Pseudo Amino Acid Composition: An Approach from Multi-Scale Energy Representation and Position Specific Scoring Matrix. Protein \& Peptide Letters, 19, 890-903. https://doi.org/10.2174/092986612801619589

87. Cao, D.S., Xu, Q.S. and Liang, Y.Z. (2013) Propy: A Tool to Generate Various Modes of Chou's PseAAC. Bioinformatics, 29, 960-962. https://doi.org/10.1093/bioinformatics/btt072

88. Chang, T.H., Wu, L.C., Lee, T.Y., Chen, S.P., Huang, H.D. and Horng, J.T. (2013) EuLoc: A Web-Server for Accurately Predict Protein Subcellular Localization in Eukaryotes by Incorporating Various Features of Sequence Segments into the General form of Chou's PseAAC. Journal of Computer-Aided Molecular Design, 27, 91-103. https://doi.org/10.1007/s10822-012-9628-0

89. Chen, Y.K. and Li, K.B. (2013) Predicting Membrane Protein Types by Incorporating Protein Topology, Domains, Signal Peptides, and Physicochemical Properties into the General Form of Chou's Pseudo Amino Acid Composition. Journal of Theoretical Biology, 318, 1-12. https://doi.org/10.1016/j.jtbi.2012.10.033

90. Fan, G.-L., Li, Q.-Z. and Zuo, Y.-C. (2013) Predicting Acidic and Alkaline Enzymes by Incorporating the Average Chemical Shift and Gene Ontology Informations into the General Form of Chou's PseAAC. Process Biochemistry, 48, 1048-1053. https://doi.org/10.1016/j.procbio.2013.05.012

91. Fan, G.L. and Li, Q.Z. (2013) Discriminating Bioluminescent Proteins by Incorporating Average Chemical Shift and Evolutionary Information into the General Form of Chou's Pseudo Amino Acid Composition. Journal of Theoretical Biology, 334, 45-51. https://doi.org/10.1016/j.jtbi.2013.06.003

92. Georgiou, D.N., Karakasidis, T.E. and Megaritis, A.C. (2013) A Short Survey on Genetic Sequences, Chou's Pseudo Amino Acid Composition and Its Combination with Fuzzy Set Theory. The Open Bioinformatics Journal, 7, 41-48. https://doi.org/10.2174/1875036201307010041

93. Gupta, M.K., Niyogi, R. and Misra, M. (2013) An Alignment-Free Method to Find Similarity among Protein Sequences via the General Form of Chou's Pseudo Amino Acid Composition. SAR and QSAR in Environmental Research, 24, 597-609. https://doi.org/10.1080/1062936X.2013.773378

94. Huang, C. and Yuan, J. (2013) Using Radial Basis Function on the General Form of Chou's Pseudo Amino Acid Composition and PSSM to Predict Subcellular Locations of Proteins with Both Single and Multiple Sites. Biosystems, 113, 50-57. https://doi.org/10.1016/j.biosystems.2013.04.005

95. Huang, C. and Yuan, J.Q. (2013) A Multilabel Model Based on Chou's Pseudo Amino Acid Composition for 
Identifying Membrane Proteins with Both Single and Multiple Functional Types. The Journal of Membrane Biology, 246, 327-334. https://doi.org/10.1007/s00232-013-9536-9

96. Huang, C. and Yuan, J.Q. (2013) Predicting Protein Subchloroplast Locations with Both Single and Multiple Sites via Three Different Modes of Chou's Pseudo Amino Acid Compositions. Journal of Theoretical Biology, 335, 205-212. https://doi.org/10.1016/j.jtbi.2013.06.034

97. Khosravian, M., Faramarzi, F.K., Beigi, M.M., Behbahani, M. and Mohabatkar, H. (2013) Predicting Antibacterial Peptides by the Concept of Chou's Pseudo Amino Acid Composition and Machine Learning Methods. Protein \& Peptide Letters, 20, 180-186. https://doi.org/10.2174/092986613804725307

98. Lin, H., Ding, C., Yuan, L.-F., Chen, W., Ding, H., Li, Z.-Q., Guo, F.-B., Huang, J. and Rao, N.-N. (2013) Predicting Subchloroplast Locations of Proteins Based on the General Form of Chou's Pseudo Amino Acid Composition: Approached from Optimal Tripeptide Composition. International Journal of Biomethmatics, 6, Article ID: 1350003. https://doi.org/10.1142/S1793524513500034

99. Liu, B., Wang, X., Zou, Q., Dong, Q. and Chen, Q. (2013) Protein Remote Homology Detection by Combining Chou's Pseudo Amino Acid Composition and Profile-Based Protein Representation. Molecular Informatics, 32, 775-782. https://doi.org/10.1002/minf.201300084

100. Mohabatkar, H., Beigi, M.M., Abdolahi, K. and Mohsenzadeh, S. (2013) Prediction of Allergenic Proteins by Means of the Concept of Chou's Pseudo Amino Acid Composition and a Machine Learning Approach. Medicinal Chemistry, 9, 133-137. https://doi.org/10.2174/157340613804488341

101. Pacharawongsakda, E. and Theeramunkong, T. (2013) Predict Subcellular Locations of Singleplex and Multiplex Proteins by Semi-Supervised Learning and Dimension-Reducing General Mode of Chou's PseAAC. IEEE Transactions on Nanobioscience, 12, 311-320. https://doi.org/10.1109/TNB.2013.2272014

102. Qin, Y.F., Zheng, L. and Huang, J. (2013) Locating Apoptosis Proteins by Incorporating the Signal Peptide Cleavage Sites into the General Form of Chou's Pseudo Amino Acid Composition. International Journal of Quantum Chemistry, 113, 1660-1667. https://doi.org/10.1002/qua.24383

103. Sarangi, A.N., Lohani, M. and Aggarwal, R. (2013) Prediction of Essential Proteins in Prokaryotes by Incorporating Various Physico-Chemical Features into the General form of Chou's Pseudo Amino Acid Composition. Protein \& Peptide Letters, 20, 781-795. https://doi.org/10.2174/0929866511320070008

104. Wan, S., Mak, M.W. and Kung, S.Y. (2013) GOASVM: A Subcellular Location Predictor by Incorporating Term-Frequency Gene Ontology into the General Form of Chou's Pseudo Amino Acid Composition. Journal of Theoretical Biology, 323, 40-48. https://doi.org/10.1016/j.jtbi.2013.01.012

105. Wang, X., Li, G.Z. and Lu, W.C. (2013) Virus-ECC-mPLoc: A Multi-Label Predictor for Predicting the Subcellular Localization of Virus Proteins with Both Single and Multiple Sites Based on a General Form of Chou's Pseudo Amino Acid Composition. Protein \& Peptide Letters, 20, 309-317. https://doi.org/10.2174/092986613804910608

106. Niu, X.H., et al. (2013) Using the Concept of Chou's Pseudo Amino Acid Composition to Predict Protein Solubility: An Approach with Entropies in Information Theory. Journal of Theoretical Biology, 332, 211-217. https://doi.org/10.1016/j.jtbi.2013.03.010

107. Xie, H.L., Fu, L. and Nie, X.D. (2013) Using Ensemble SVM to Identify Human GPCRs N-Linked Glycosylation Sites Based on the General Form of Chou's PseAAC. Protein Engineering, Design and Selection, 26, 735-742. https://doi.org/10.1093/protein/gzt042

108. Du, P., Gu, S. and Jiao, Y. (2014) PseAAC-General: Fast Building Various Modes of General Form of Chou's Pseudo Amino Acid Composition for Large-Scale Protein Datasets. International Journal of Molecular Sciences, 15, 3495-3506. https://doi.org/10.3390/ijms15033495 
109. Hajisharifi, Z., Piryaiee, M., Mohammad Beigi, M., Behbahani, M. and Mohabatkar, H. (2014) Predicting Anticancer Peptides with Chou's Pseudo Amino Acid Composition and Investigating Their Mutagenicity via Ames Test. Journal of Theoretical Biology, 341, 34-40. https://doi.org/10.1016/j.jtbi.2013.08.037

110. Han, G.S., Yu, Z.G. and Anh, V. (2014) A Two-Stage SVM Method to Predict Membrane Protein Types by Incorporating Amino Acid Classifications and Physicochemical Properties into a General Form of Chou's PseAAC. Journal of Theoretical Biology, 344, 31-39. https://doi.org/10.1016/j.jtbi.2013.11.017

111. Jia, C., Lin, X. and Wang, Z. (2014) Prediction of Protein S-Nitrosylation Sites Based on Adapted Normal Distribution Bi-Profile Bayes and Chou's Pseudo Amino Acid Composition. International Journal of Molecular Sciences, 15, 10410-10423. https://doi.org/10.3390/ijms150610410

112. Kong, L., Zhang, L. and Lv, J. (2014) Accurate Prediction of Protein Structural Classes by Incorporating Predicted Secondary Structure Information into the General form of Chou's Pseudo Amino Acid Composition. Journal of Theoretical Biology, 344, 12-18. https://doi.org/10.1016/j.jtbi.2013.11.021

113. Li, L., Yu, S., Xiao, W., Li, Y., Li, M., Huang, L., Zheng, X., Zhou, S. and Yang, H. (2014) Prediction of Bacterial Protein Subcellular Localization by Incorporating Various Features into Chou's PseAAC and a Backward Feature Selection Approach. Biochimie, 104, 100-107. https://doi.org/10.1016/j.biochi.2014.06.001

114. Nanni, L., Brahnam, S. and Lumini, A. (2014) Prediction of Protein Structure Classes by Incorporating Different Protein Descriptors into General Chou's Pseudo Amino Acid Composition. Journal of Theoretical Biology, 360, 109-116. https://doi.org/10.1016/j.jtbi.2014.07.003

115. Zhang, J., Sun, P., Zhao, X. and Ma, Z. (2014) PECM: Prediction of Extracellular Matrix Proteins Using the Concept of Chou's Pseudo Amino Acid Composition. Journal of Theoretical Biology, 363, 412-418. https://doi.org/10.1016/j.jtbi.2014.08.002

116. Zhang, J., Zhao, X., Sun, P. and Ma, Z. (2014) PSNO: Predicting Cysteine S-Nitrosylation Sites by Incorporating Various Sequence-Derived Features into the General Form of Chou's PseAAC. International Journal of Molecular Sciences, 15, 11204-11219. https://doi.org/10.3390/ijms150711204

117. Zhang, L., Zhao, X. and Kong, L. (2014) Predict Protein Structural Class for Low-Similarity Sequences by Evolutionary Difference Information into the General Form of Chou's Pseudo Amino Acid Composition. Journal of Theoretical Biology, 355, 105-110. https://doi.org/10.1016/j.jtbi.2014.04.008

118. Zuo, Y.C., Peng, Y., Liu, L., Chen, W., Yang, L. and Fan, G.L. (2014) Predicting Peroxidase Subcellular Location by Hybridizing Different Descriptors of Chou's Pseudo Amino Acid Patterns. Analytical Biochemistry, 458, 14-19. https://doi.org/10.1016/j.ab.2014.04.032

119. Ali, F. and Hayat, M. (2015) Classification of Membrane Protein Types Using Voting Feature Interval in Combination with Chou's Pseudo Amino Acid Composition. Journal of Theoretical Biology, 384, 78-83.

https://doi.org/10.1016/j.jtbi.2015.07.034

120. Fan, G.L., Zhang, X.Y., Liu, Y.L., Nang, Y. and Wang, H. (2015) DSPMP: Discriminating Secretory Proteins of Malaria Parasite by Hybridizing Different Descriptors of Chou's Pseudo Amino Acid Patterns. Journal of Computational Chemistry, 36, 2317-2327. https://doi.org/10.1002/jcc.24210

121. Huang, C. and Yuan, J.Q. (2015) Simultaneously Identify Three Different Attributes of Proteins by Fusing Their Three Different Modes of Chou's Pseudo Amino Acid Compositions. Protein \& Peptide Letters, 22, 547-556. https://doi.org/10.2174/0929866522666150209151344

122. Khan, Z.U., Hayat, M. and Khan, M.A. (2015) Discrimination of Acidic and Alkaline Enzyme Using Chou's Pseudo Amino Acid Composition in Conjunction with Probabilistic Neural Network Model. Journal of Theoretical Biology, 365, 197-203. https://doi.org/10.1016/j.jtbi.2014.10.014

123. Kumar, R., Srivastava, A., Kumari, B. and Kumar, M. (2015) Prediction of Beta-Lactamase and Its Class by 
Chou's Pseudo Amino Acid Composition and Support Vector Machine. Journal of Theoretical Biology, 365, 96-103. https://doi.org/10.1016/j.jtbi.2014.10.008

124. Liu, B., Xu, J., Fan, S., Xu, R., Zhou, J.Y. and Wang, X. (2015) PseDNA-Pro: DNA-Binding Protein Identification by Combining Chou's PseAAC and Physicochemical Distance Transformation. Molecular Informatics, 34, 8-17. https://doi.org/10.1002/minf.201400025

125. Mandal, M., Mukhopadhyay, A. and Maulik, U. (2015) Prediction of Protein Subcellular Localization by Incorporating Multiobjective PSO-Based Feature Subset Selection into the General form of Chou's PseAAC. Medical \& Biological Engineering \& Computing, 53, 331-344. https://doi.org/10.1007/s11517-014-1238-7

126. Sanchez, V., Peinado, A.M., Perez-Cordoba, J.L. and Gomez, A.M. (2015) A New Signal Characterization and Signal-Based Chou's PseAAC Representation of Protein Sequences. Journal of Bioinformatics and Computational Biology, 13, Article ID: 1550024. https://doi.org/10.1142/S0219720015500249

127. Wang, X., Zhang, W., Zhang, Q. and Li, G.Z. (2015) MultiP-SChlo: Multi-Label Protein Subchloroplast Localization Prediction with Chou's Pseudo Amino Acid Composition and a Novel Multi-Label Classifier. Bioinformatics, 31, 2639-2645. https://doi.org/10.1093/bioinformatics/btv212

128. Jiao, Y.S. and Du, P.F. (2016) Prediction of Golgi-Resident Protein Types Using General Form of Chou's Pseudo Amino Acid Compositions: Approaches with Minimal Redundancy Maximal Relevance Feature Selection. Journal of Theoretical Biology, 402, 38-44. https://doi.org/10.1016/j.jtbi.2016.04.032

129. Kabir, M. and Hayat, M. (2016) iRSpot-GAEnsC: Identifying Recombination Spots via Ensemble Classifier and Extending the Concept of Chou's PseAAC to Formulate DNA Samples. Molecular Genetics and Genomics, 291, 285-296. https://doi.org/10.1007/s00438-015-1108-5

130. Tahir, M. and Hayat, M. (2016) iNuc-STNC: A Sequence-Based Predictor for Identification of Nucleosome Positioning in Genomes by Extending the Concept of SAAC and Chou's PseAAC. Molecular BioSystems, 12, 2587-2593. https://doi.org/10.1039/C6MB00221H

131. Tang, H., Chen, W. and Lin, H. (2016) Identification of Immunoglobulins Using Chou's Pseudo Amino Acid Composition with Feature Selection Technique. Molecular BioSystems, 12, 1269-1275. https://doi.org/10.1039/C5MB00883B

132. Zou, H.L. and Xiao, X. (2016) Predicting the Functional Types of Singleplex and Multiplex Eukaryotic Membrane Proteins via Different Models of Chou's Pseudo Amino Acid Compositions. The Journal of Membrane Biology, 249, 23-29. https://doi.org/10.1007/s00232-015-9830-9

133. Huo, H., Li, T., Wang, S., Lv, Y., Zuo, Y. and Yang, L. (2017) Prediction of Presynaptic and Postsynaptic Neurotoxins by Combining Various Chou's Pseudo Components. Scientific Reports, 7, Article No. 5827. https://doi.org/10.1038/s41598-017-06195-y

134. Ju, Z. and He, J.J. (2017) Prediction of Lysine Propionylation Sites Using Biased SVM and Incorporating Four Different Sequence Features into Chou's PseAAC. Journal of Molecular Graphics and Modelling, 76, 356-363. https://doi.org/10.1016/j.jmgm.2017.07.022

135. Rahimi, M., Bakhtiarizadeh, M.R. and Mohammadi-Sangcheshmeh, A. (2017) OOgenesis_Pred: A Sequence-Based Method for Predicting Oogenesis Proteins by Six Different Modes of Chou's Pseudo Amino Acid Composition. Journal of Theoretical Biology, 414, 128-136. https://doi.org/10.1016/j.jtbi.2016.11.028

136. Tripathi, P. and Pandey, P.N. (2017) A Novel Alignment-Free Method to Classify Protein Folding Types by Combining Spectral Graph Clustering with Chou's Pseudo Amino Acid Composition. Journal of Theoretical Biology, 424, 49-54. https://doi.org/10.1016/j.jtbi.2017.04.027

137. Yu, B., Li, S., Qiu, W.Y., Chen, C., Chen, R.X., Wang, L., Wang, M.H. and Zhang, Y. (2017) Accurate Prediction of Subcellular Location of Apoptosis Proteins Combining Chou's PseAAC and PsePSSM Based on Wavelet De- 
noising. Oncotarget, 8, 107640-107665. https://doi.org/10.18632/oncotarget.22585

138. Yu, B., Lou, L., Li, S., Zhang, Y., Qiu, W., Wu, X., Wang, M. and Tian, B. (2017) Prediction of Protein Structural Class for Low-Similarity Sequences Using Chou's Pseudo Amino Acid Composition and Wavelet Denoising. Journal of Molecular Graphics and Modelling, 76, 260-273. https://doi.org/10.1016/j.jmgm.2017.07.012

139. Ahmad, J. and Hayat, M. (2018) MFSC: Multi-Voting Based Feature Selection for Classification of Golgi Proteins by Adopting the General form of Chou's PseAAC Components. Journal of Theoretical Biology, 463, 99-109. https://doi.org/10.1016/j.jtbi.2018.12.017

140. Akbar, S. and Hayat, M. (2018) iMethyl-STTNC: Identification of N(6)-Methyladenosine Sites by Extending the Idea of SAAC into Chou's PseAAC to Formulate RNA Sequences. Journal of Theoretical Biology, 455, 205-211. https://doi.org/10.1016/j.jtbi.2018.07.018

141. Al Maruf, M.A. and Shatabda, S. (2018) iRSpot-SF: Prediction of Recombination Hotspots by Incorporating Sequence Based Features into Chou's Pseudo Components. Genomics, 111, 966-972. https://doi.org/10.1016/j.ygeno.2018.06.003

142. Arif, M., Hayat, M. and Jan, Z. (2018) iMem-2LSAAC: A Two-Level Model for Discrimination of Membrane Proteins and Their Types by Extending the Notion of SAAC into Chou's Pseudo Amino Acid Composition. Journal of Theoretical Biology, 442, 11-21. https://doi.org/10.1016/j.jtbi.2018.01.008

143. Contreras-Torres, E. (2018) Predicting Structural Classes of Proteins by Incorporating Their Global and Local Physicochemical and Conformational Properties into General Chou's PseAAC. Journal of Theoretical Biology, 454, 139-145. https://doi.org/10.1016/j.jtbi.2018.05.033

144. Cui, X., Yu, Z., Yu, B., Wang, M., Tian, B. and Ma, Q. (2018) UbiSitePred: A Novel Method for Improving the Accuracy of Ubiquitination Sites Prediction by Using LASSO to Select the Optimal Chou's Pseudo Components. Chemometrics and Intelligent Laboratory Systems.

145. Fu, X., Zhu, W., Liso, B., Cai, L., Peng, L. and Yang, J. (2018) Improved DNA-Binding Protein Identification by Incorporating Evolutionary Information into the Chou's PseAAC. IEEE Access, 6, 66545-66556.

146. Javed, F. and Hayat, M. (2018) Predicting Subcellular Localizations of Multi-Label Proteins by Incorporating the Sequence Features into Chou's PseAAC. Genomics, 111, 1325-1332. https://doi.org/10.1016/j.ygeno.2018.09.004

147. Mei, J. and Zhao, J. (2018) Prediction of HIV-1 and HIV-2 Proteins by Using Chou's Pseudo Amino Acid Compositions and Different Classifiers. Scientific Reports, 8, Article No. 2359.

https://doi.org/10.1038/s41598-018-20819-x

148. Mousavizadegan, M. and Mohabatkar, H. (2018) Computational Prediction of Antifungal Peptides via Chou's PseAAC and SVM. Journal of Bioinformatics and Computational Biology, 16, Article ID: 1850016. https://doi.org/10.1142/S0219720018500166

149. Qiu, W., Li, S., Cui, X., Yu, Z., Wang, M., Du, J., Peng, Y. and Yu, B. (2018) Predicting Protein Submitochondrial Locations by Incorporating the Pseudo-Position Specific Scoring Matrix into the General Chou's Pseudo-Amino Acid Composition. Journal of Theoretical Biology, 450, 86-103.

https://doi.org/10.1016/j.jtbi.2018.04.026

150. Zhang, L. and Kong, L. (2018) iRSpot-ADPM: Identify Recombination Spots by Incorporating the Associated Dinucleotide Product Model into Chou's Pseudo Components. Journal of Theoretical Biology, 441, 1-8. https://doi.org/10.1016/j.jtbi.2017.12.025

151. Zhang, S. and Liang, Y. (2018) Predicting Apoptosis Protein Subcellular Localization by Integrating Auto-Cross Correlation and PSSM into Chou's PseAAC. Journal of Theoretical Biology, 457, 163-169.

https://doi.org/10.1016/j.jtbi.2018.08.042

152. Zhang, S., Yang, K., Lei, Y. and Song, K. (2018) iRSpot-DTS: Predict Recombination Spots by Incorporating the 
Dinucleotide-Based Spare-Cross Covariance Information into Chou's Pseudo Components. Genomics, 11, 457-464.

153. Zhao, W., Wang, L., Zhang, T.X., Zhao, Z.N. and Du, P.F. (2018) A Brief Review on Software Tools in Generating Chou's Pseudo-Factor Representations for All Types of Biological Sequences. Protein \& Peptide Letters, 25, 822-829. https://doi.org/10.2174/0929866525666180905111124

154. Ahmad, J. and Hayat, M. (2018) MFSC: Multi-Voting Based Feature Selection for Classification of Golgi Proteins by Adopting the General form of Chou's PseAAC Components. Journal of Theoretical Biology, 463, 99-109. https://doi.org/10.1016/j.jtbi.2018.12.017

155. Al Maruf, M.A. and Shatabda, S. (2019) iRSpot-SF: Prediction of Recombination Hotspots by Incorporating Sequence Based Features into Chou's Pseudo Components. Genomics, 111, 966-972.

https://doi.org/10.1016/j.ygeno.2018.06.003

156. Butt, A.H., Rasool, N. and Khan, Y.D. (2019) Prediction of Antioxidant Proteins by Incorporating Statistical Moments Based Features into Chou's PseAAC. Journal of Theoretical Biology, 473, 1-8.

https://doi.org/10.1016/j.jtbi.2019.04.019

157. Javed, F. and Hayat, M. (2018) Predicting Subcellular Localizations of Multi-Label Proteins by Incorporating the Sequence Features into Chou's PseAAC. Genomics, 111, 1325-1332. https://doi.org/10.1016/j.ygeno.2018.09.004

158. Nosrati, M., Mohabatkar, H. and Behbahani, M. (2019) Introducing of an Integrated Artificial Neural Network and Chou's Pseudo Amino Acid Composition Approach for Computational Epitope-Mapping of Crimean-Congo Haemorrhagic Fever Virus Antigens. International Immunopharmacology, 78, Article ID: 106020. https://www.sciencedirect.com/science/article/pii/S1567576919321277.

https://doi.org/10.1016/j.intimp.2019.106020

159. Pan, Y., Wang, S., Zhang, Q., Lu, Q., Su, D., Zuo, Y. and Yang, L. (2019) Analysis and Prediction of Animal Toxins by Various Chou's Pseudo Components and Reduced Amino Acid Compositions. Journal of Theoretical Biology, 462, 221-229. https://doi.org/10.1016/j.jtbi.2018.11.010

160. Tahir, M., Hayat, M. and Khan, S.A. (2019) iNuc-ext-PseTNC: An Efficient Ensemble Model for Identification of Nucleosome Positioning by Extending the Concept of Chou's PseAAC to Pseudo-Tri-Nucleotide Composition. Molecular Genetics and Genomics, 294, 199-210. https://doi.org/10.1007/s00438-018-1498-2

161. Tahir, M., Tayara, H. and Chong, K.T. (2019) iRNA-PseKNC(2methyl): Identify RNA 2'-O-methylation Sites by Convolution Neural Network and Chou's Pseudo Components. Journal of Theoretical Biology, 465, 1-6. https://doi.org/10.1016/j.jtbi.2018.12.034

162. Tian, B., Wu, X., Chen, C., Qiu, W., Ma, Q. and Yu, B. (2019) Predicting Protein-Protein Interactions by Fusing Various Chou's Pseudo Components and Using Wavelet Denoising Approach. Journal of Theoretical Biology, 462, 329-346. https://doi.org/10.1016/j.jtbi.2018.11.011

163. Zhang, L. and Kong, L. (2019) iRSpot-PDI: Identification of Recombination Spots by Incorporating Dinucleotide Property Diversity Information into Chou's Pseudo Components. Genomics, 111, 457-464.

https://doi.org/10.1016/j.ygeno.2018.03.003

164. Zhang, S., Yang, K., Lei, Y. and Song, K. (2019) iRSpot-DTS: Predict Recombination Spots by Incorporating the Dinucleotide-Based Spare-Cross Covariance Information into Chou's Pseudo Components. Genomics, 111, 1760-1770. https://doi.org/10.1016/j.ygeno.2018.11.031

165. Hayat, M. and Iqbal, N. (2014) Discriminating Protein Structure Classes by Incorporating Pseudo Average Chemical Shift to Chou's General PseAAC and Support Vector Machine. Computer Methods and Programs in Biomedicine, 116, 184-192. https://doi.org/10.1016/j.cmpb.2014.06.007

166. Ahmad, S., Kabir, M. and Hayat, M. (2015) Identification of Heat Shock Protein Families and J-Protein Types 
by Incorporating Dipeptide Composition into Chou's General PseAAC. Computer Methods and Programs in Biomedicine, 122, 165-174. https://doi.org/10.1016/j.cmpb.2015.07.005

167. Dehzangi, A., Heffernan, R., Sharma, A., Lyons, J., Paliwal, K. and Sattar, A. (2015) Gram-Positive and Gram-Negative Protein Subcellular Localization by Incorporating Evolutionary-Based Descriptors into Chou's General PseAAC. Journal of Theoretical Biology, 364, 284-294. https://doi.org/10.1016/j.jtbi.2014.09.029

168. Sharma, R., Dehzangi, A., Lyons, J., Paliwal, K., Tsunoda, T. and Sharma, A. (2015) Predict Gram-Positive and Gram-Negative Subcellular Localization via Incorporating Evolutionary Information and Physicochemical Features Into Chou's General PseAAC. IEEE Transactions on NanoBioscience, 14, 915-926.

https://doi.org/10.1109/TNB.2015.2500186

169. Zhang, M., Zhao, B. and Liu, X. (2015) Predicting Industrial Polymer Melt Index via Incorporating Chaotic Characters into Chou's General PseAAC. Chemometrics and Intelligent Laboratory Systems (CHEMOLAB), 146, 232-240. https://doi.org/10.1016/j.chemolab.2015.05.028

170. Zhang, S.L. (2015) Accurate Prediction of Protein Structural Classes by Incorporating PSSS and PSSM into Chou's General PseAAC. Chemometrics and Intelligent Laboratory Systems (CHEMOLAB), 142, 28-35. https://doi.org/10.1016/j.chemolab.2015.01.004

171. Ahmad, K., Waris, M. and Hayat, M. (2016) Prediction of Protein Submitochondrial Locations by Incorporating Dipeptide Composition into Chou's General Pseudo Amino Acid Composition. The Journal of Membrane Biology, 249, 293-304. https://doi.org/10.1007/s00232-015-9868-8

172. Behbahani, M., Mohabatkar, H. and Nosrati, M. (2016) Analysis and Comparison of Lignin Peroxidases between Fungi and Bacteria Using Three Different Modes of Chou's General Pseudo Amino Acid Composition. Journal of Theoretical Biology, 411, 1-5. https://doi.org/10.1016/j.jtbi.2016.09.001

173. Fan, G.L., Liu, Y.L. and Wang, H. (2016) Identification of Thermophilic Proteins by Incorporating Evolutionary and Acid Dissociation Information into Chou's General Pseudo Amino Acid Composition. Journal of Theoretical Biology, 407, 138-142. https://doi.org/10.1016/j.jtbi.2016.07.010

174. Ju, Z., Cao, J.Z. and Gu, H. (2016) Predicting Lysine Phosphoglycerylation with Fuzzy SVM by Incorporating k-Spaced Amino Acid Pairs into Chou's General PseAAC. Journal of Theoretical Biology, 397, 145-150. https://doi.org/10.1016/j.jtbi.2016.02.020

175. Tiwari, A.K. (2016) Prediction of G-Protein Coupled Receptors and Their Subfamilies by Incorporating Various Sequence Features into Chou's General PseAAC. Computer Methods and Programs in Biomedicine, 134, 197-213. https://doi.org/10.1016/j.cmpb.2016.07.004

176. Xu, C., Sun, D., Liu, S. and Zhang, Y. (2016) Protein Sequence Analysis by Incorporating Modified Chaos Game and Physicochemical Properties into Chou's General Pseudo Amino Acid Composition. Journal of Theoretical Biology, 406, 105-115. https://doi.org/10.1016/j.jtbi.2016.06.034

177. Zou, H.L. and Xiao, X. (2016) Classifying Multifunctional Enzymes by Incorporating Three Different Models into Chou's General Pseudo Amino Acid Composition. The Journal of Membrane Biology, 249, 561-567. https://doi.org/10.1007/s00232-016-9904-3

178. Jiao, Y.S. and Du, P.F. (2017) Predicting Protein Submitochondrial Locations by Incorporating the Positional-Specific Physicochemical Properties into Chou's General Pseudo-Amino Acid Compositions. Journal of Theoretical Biology, 416, 81-87. https://doi.org/10.1016/j.jtbi.2016.12.026

179. Ju, Z. and He, J.J. (2017) Prediction of Lysine Crotonylation Sites by Incorporating the Composition of k-Spaced Amino Acid Pairs into Chou's General PseAAC. Journal of Molecular Graphics and Modelling, 77, 200-204. https://doi.org/10.1016/j.jmgm.2017.08.020

180. Khan, M., Hayat, M., Khan, S.A. and Iqbal, N. (2017) Unb-DPC: Identify Mycobacterial Membrane Protein 
Types by Incorporating Un-Biased Dipeptide Composition into Chou's General PseAAC. Journal of Theoretical Biology, 415, 13-19. https://doi.org/10.1016/j.jtbi.2016.12.004

181. Liang, Y. and Zhang, S. (2017) Predict Protein Structural Class by Incorporating Two Different Modes of Evolutionary Information into Chou's General Pseudo Amino Acid Composition. Journal of Molecular Graphics and Modelling, 78, 110-117. https://doi.org/10.1016/j.jmgm.2017.10.003

182. Meher, P.K., Sahu, T.K., Saini, V. and Rao, A.R. (2017) Predicting Antimicrobial Peptides with Improved Accuracy by Incorporating the Compositional, Physico-Chemical and Structural Features into Chou's General PseAAC. Scientific Reports, 7, Article No. 42362. https://doi.org/10.1038/srep42362

183. Qiu, W.R., Zheng, Q.S., Sun, B.Q. and Xiao, X. (2017) Multi-iPPseEvo: A Multi-Label Classifier for Identifying Human Phosphorylated Proteins by Incorporating Evolutionary Information into Chou's General PseAAC via Grey System Theory. Molecular Informatics, 36, UNSP 1600085. https://doi.org/10.1002/minf.201600085

184. Xu, C., Ge, L., Zhang, Y., Dehmer, M. and Gutman, I. (2017) Prediction of Therapeutic Peptides by Incorporating q-Wiener Index into Chou's General PseAAC. Journal of Biomedical Informatics, 75, 63-69.

185. Butt, A.H., Rasool, N. and Khan, Y.D. (2018) Predicting Membrane Proteins and Their Types by Extracting Various Sequence Features into Chou's General PseAAC. Molecular Biology Reports, 45, 2295-2306.

186. Ghauri, A.W., Khan, Y.D., Rasool, N., Khan, S.A. and Chou, K.C. (2018) pNitro-Tyr-PseAAC: Predict Nitrotyrosine Sites in Proteins by Incorporating Five Features into Chou's General PseAAC. Current Pharmaceutical Design, 24, 4034-4043. https://doi.org/10.2174/1381612825666181127101039

187. Ju, Z. and Wang, S.Y. (2018) Prediction of Citrullination Sites by Incorporating k-Spaced Amino Acid Pairs into Chou's General Pseudo Amino Acid Composition. Gene, 664, 78-83. https://doi.org/10.1016/j.gene.2018.04.055

188. Krishnan, M.S. (2018) Using Chou's General PseAAC to Analyze the Evolutionary Relationship of Receptor Associated Proteins (RAP) with Various Folding Patterns of Protein Domains. Journal of Theoretical Biology, 445, 62-74. https://doi.org/10.1016/j.jtbi.2018.02.008

189. Liang, Y. and Zhang, S. (2018) Identify Gram-Negative Bacterial Secreted Protein Types by Incorporating Different Modes of PSSM into Chou's General PseAAC via Kullback-Leibler Divergence. Journal of Theoretical Biology, 454, 22-29. https://doi.org/10.1016/j.jtbi.2018.05.035

190. Mei, J., Fu, Y. and Zhao, J. (2018) Analysis and Prediction of Ion Channel Inhibitors by Using Feature Selection and Chou's General Pseudo Amino Acid Composition. Journal of Theoretical Biology, 456, 41-48. https://doi.org/10.1016/j.jtbi.2018.07.040

191. Mei, J. and Zhao, J. (2018) Analysis and Prediction of Presynaptic and Postsynaptic Neurotoxins by Chou's General Pseudo Amino Acid Composition and Motif Features. Journal of Theoretical Biology, 427, 147-153. https://doi.org/10.1016/j.jtbi.2018.03.034

192. Rahman, S.M., Shatabda, S., Saha, S., Kaykobad, M. and Sohel Rahman, M. (2018) DPP-PseAAC: A DNA-Binding Protein Prediction Model Using Chou's General PseAAC. Journal of Theoretical Biology, 452, 22-34. https://doi.org/10.1016/j.jtbi.2018.05.006

193. Sabooh, M.F., Iqbal, N., Khan, M., Khan, M. and Maqbool, H.F. (2018) Identifying 5-Methylcytosine Sites in RNA Sequence Using Composite Encoding Feature into Chou's PseKNC. Journal of Theoretical Biology, 452, 1-9. https://doi.org/10.1016/j.jtbi.2018.04.037

194. Sankari, E.S. and Manimegalai, D.D. (2018) Predicting Membrane Protein Types by Incorporating a Novel Feature Set into Chou's General PseAAC. Journal of Theoretical Biology, 455, 319-328. https://doi.org/10.1016/j.jtbi.2018.07.032

195. Srivastava, A., Kumar, R. and Kumar, M. (2018) BlaPred: Predicting and Classifying Beta-Lactamase Using a 3-Tier Prediction System via Chou's General PseAAC. Journal of Theoretical Biology, 457, 29-36. 
https://doi.org/10.1016/j.jtbi.2018.08.030

196. Zhang, S. and Duan, X. (2018) Prediction of Protein Subcellular Localization with Oversampling Approach and Chou's General PseAAC. Journal of Theoretical Biology, 437, 239-250. https://doi.org/10.1016/j.jtbi.2017.10.030

197. Adilina, S., Farid, D.M. and Shatabda, S. (2019) Effective DNA Binding Protein Prediction by Using Key Features via Chou's General PseAAC. Journal of Theoretical Biology, 460, 64-78.

https://doi.org/10.1016/j.jtbi.2018.10.027

198. Behbahani, M., Nosrati, M., Moradi, M. and Mohabatkar, H. (2019) Using Chou's General Pseudo Amino Acid Composition to Classify Laccases from Bacterial and Fungal Sources via Chou's Five-Step Rule. Applied Biochemistry and Biotechnology. https://doi.org/10.1007/s12010-019-03141-8

199. Chen, G., Cao, M., Yu, J., Guo, X. and Shi, S. (2019) Prediction and Functional Analysis of Prokaryote Lysine Acetylation Site by Incorporating Six Types of Features into Chou's General PseAAC. Journal of Theoretical Biology, 461, 92-101. https://doi.org/10.1016/j.jtbi.2018.10.047

200. Shen, Y., Tang, J. and Guo, F. (2019) Identification of Protein Subcellular Localization via Integrating Evolutionary and Physicochemical Information into Chou's General PseAAC. Journal of Theoretical Biology, 462, 230-239. https://doi.org/10.1016/j.jtbi.2018.11.012

201. Wang, L., Zhang, R. and Mu, Y. (2019) Fu-SulfPred: Identification of Protein S-Sulfenylation Sites by Fusing Forests via Chou's General PseAAC. Journal of Theoretical Biology, 461, 51-58. https://doi.org/10.1016/j.jtbi.2018.10.046

202. Xiao, X., Cheng, X., Chen, G., Mao, Q. and Chou, K.C. (2019) pLoc_bal-mVirus: Predict Subcellular Localization of Multi-Label Virus Proteins by Chou's General PseAAC and IHTS Treatment to Balance Training Dataset. Medicinal Chemistry, 15, 496-509. https://doi.org/10.2174/1573406415666181217114710

203. Chou, K.C. (2019) Advance in Predicting Subcellular Localization of Multi-Label Proteins and Its Implication for Developing Multi-Target Drugs. Current Medicinal Chemistry, 26, 4918-4943.

https://www.eurekaselect.com/172010/article https://doi.org/10.2174/0929867326666190507082559

204. Chou, K.C. (2019) Two Kinds of Metrics for Computational Biology. Genomics. https://www.sciencedirect.com/science/article/pii/S0888754319304604?via\%3Dihub

205. Chou, K.C. (2019) Proposing Pseudo Amino Acid Components Is an Important Milestone for Proteome and Genome Analyses. International Journal for Peptide Research and Therapeutics.

https://link.springer.com/article/10.1007\%2Fs10989-019-09910-7

206. Chou, K.C. (2019) An Insightful Recollection for Predicting Protein Subcellular Locations in Multi-Label Systems. Genomics. https://www.sciencedirect.com/science/article/pii/S0888754319304604?via\%3Dihub

207. Chou, K.C. (2019) Progresses in Predicting Post-Translational Modification. International Journal of Peptide Research and Therapeutics. https://link.springer.com/article/10.1007\%2Fs10989-019-09893-5

208. Chou, K.C. (2019) An Insightful Recollection Since the Distorted Key Theory Was Born about 23 Years Ago. Genomics. https://www.sciencedirect.com/science/article/pii/S0888754319305543?via\%3Dihub

209. Chou, K.C. (2019) Artificial Intelligence (AI) Tools Constructed via the 5-Steps Rule for Predicting Post-Translational Modifications. Trends in Artificial Intelligence, 3, 60-74.

https://doi.org/10.36959/643/304

210. Chou, K.C. (2020) An Insightful 20-Year Recollection Since the Birth of Pseudo Amino Acid Components. Amino Acids. (In Press)

211. Liu, B. (2018) BioSeq-Analysis: A Platform for DNA, RNA, and Protein Sequence Analysis Based on Machine Learning Approaches. Briefings in Bioinformatics, 20, 1280-1294. 
212. Liu, B., Gao, X. and Zhang, H. (2019) BioSeq-Analysis2.0: An Updated Platform for Analyzing DNA, RNA and Protein Sequences at Sequence Level and Residue Level Based on Machine Learning Approaches. Nucleic Acids Research, 47, e127. https://doi.org/10.1093/nar/gkz740

213. Chou, K.C. (2019) The Cradle of Gordon Life Science Institute and Its Development and Driving Force. Int J Biol Genetics, 1, 1-28.

214. Chou, K.C. (2019) Showcase to Illustrate How the Web-Server iDNA6mA-PseKNC Is Working. Journal of Pathology Research Reviews \& Reports, 1, 1-15.

215. Chou, K.C. (2019) The pLoc_bal-mPlant Is a Powerful Artificial Intelligence Tool for Predicting the Subcellular Localization of Plant Proteins Purely Based on Their Sequence Information. International Journal of Nutrition Sciences, 4, 1037.

216. Chou, K.C., Cheng, X. and Xiao, X. (2019) pLoc_bal-mEuk: Predict Subcellular Localization of Eukaryotic Proteins by General PseAAC and Quasi-Balancing Training Dataset. Medicinal Chemistry, 15, 472-485. https://doi.org/10.2174/1573406415666181218102517

217. Chou, K.C. (2019) Showcase to Illustrate How the Web-Server iNitro-Tyr Is Working. Glo J of Com Sci and Infor Tec., 2, 1-16.

218. Chou, K.C. (2019) The pLoc_bal-mAnimal Is a Powerful Artificial Intelligence Tool for Predicting the Subcellular Localization of Animal Proteins Based on Their Sequence Information Alone. Scientific Journal of Biometrics \& Biostatistics, 2, 1-13.

219. Chou, K.C. (2020) Showcase to Illustrate How the Webserver pLoc_bal-mEuk Is Working. Biomedical Journal of Scientific \& Technical Research.

220. Chou, K.C. (2020) The pLoc_bal-mGneg Predictor Is a Powerful Web-Server for Identifying the Subcellular Localization of Gram-Negative Bacterial Proteins Based on their Sequences Information Alone. ijSci, 9, 27-34. https://doi.org/10.18483/ijSci.2248

221. Chou, K.C. (2020) How the Artificial Intelligence Tool iRNA-2methyl Is Working for RNA 2'-Omethylation Sites. Journal of Medical Care Research and Review, 3, 348-366.

222. Chou, K.-C. (2020) Showcase to Illustrate How the Web-Server iKcr-PseEns Is Working. Journal of Medical Care Research and Review, 3, 331-347.

223. Chou, K.C. (2020) The pLoc_bal-mVirus Is a Powerful Artificial Intelligence Tool for Predicting the Subcellular Localization of Virus Proteins According to Their Sequence Information Alone. J Gent \& Genome, 4.

224. Chou, K.C. (2019) How the Artificial Intelligence Tool iSNO-PseAAC Is Working in Predicting the Cysteine S-Nitrosylation Sites in Proteins. Journal of Stem Cell Research and Medicine, 4, 1-9.

225. Chou, K.C. (2020) Showcase to Illustrate How the Web-Server iRNA-Methyl Is Working. Journal of Molecular Genetics, 3, 1-7.

226. Chou, K.C. (2020) How the Artificial Intelligence Tool iRNA-PseU Is Working in Predicting the RNA Pseudouridine Sites. Biomedical Journal of Scientific \& Technical Research. 